\title{
Usefulness of a clutch cutter combined with an S-O clip in improving stability when opening the pocket in the pocket-creation method
}

The pocket-creation method (PCM) is a useful resection technique that has been developed to overcome difficulties in colorectal endoscopic submucosal dissection (ESD) [1,2]. However, this technique itself poses certain challenges in resection when opening the pocket, particularly when there are considerable respiratory changes. Here, we report the usefulness of combining a clutch cutter [3] - a scissor-type knife - with an S-O clip [4] for overcoming instability when opening the pocket in the PCM.

A 76-year-old man underwent ESD for a 23-mm type lla tumor on the cecum. Marked respiratory changes were observed. We first created a pocket using a clutch cutter. Next, adequate dissection directly beneath the lesion was performed under a stable visual field. When opening the pocket, marked respiratory changes were observed again. An S-O clip was attached to the anal side of the lesion, and once traction was obtained ( $\vee$ Fig. 1), the surrounding normal mucosa and submucosa were cut in a manner similar to cutting paper (paper cutting technique $[P C T])$, and the tumor was

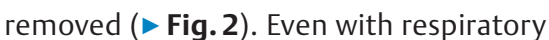
changes, resection could be safely performed because the lesion was anchored by the S-O clip, as well as by the clutch cutter, and the procedure was completed without any complications ( video 1).

Previously, a tip-type knife was used for PCM; however, for lesions beyond the sigmoid colon with major respiratory changes, instability when opening the pocket was frequently experienced despite the use of an S-O clip. This problem was subsequently overcome by the combined use of a clutch cutter only when opening the pocket. We present this video report of the PCT as an aid for novice surgeons performing colorectal ESD.

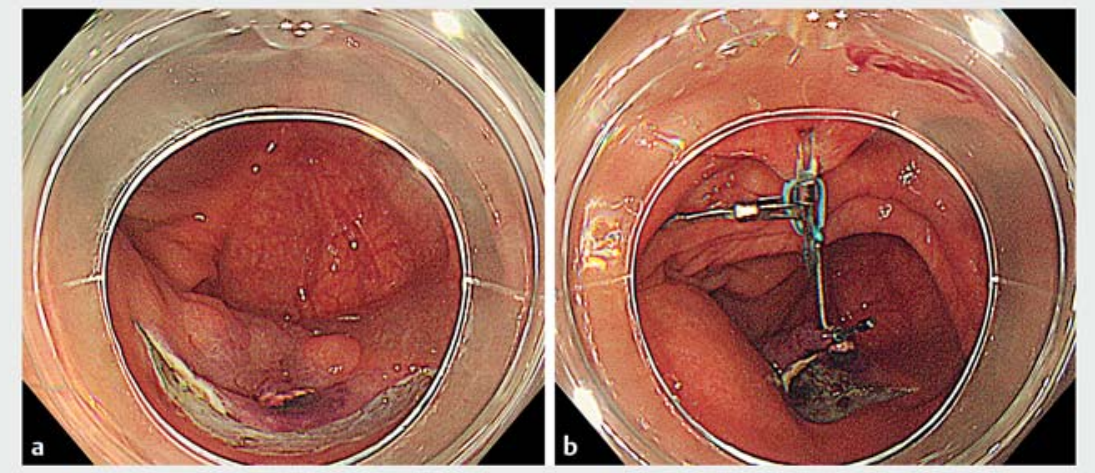

- Fig. 1 Figure showing a submucosal pocket that was created and the lesion with an S-O clip attached. a We created a submucosal pocket under most of the lesion using a clutch cutter. b An S-O clip was attached to the anal side of the lesion, and traction was obtained.

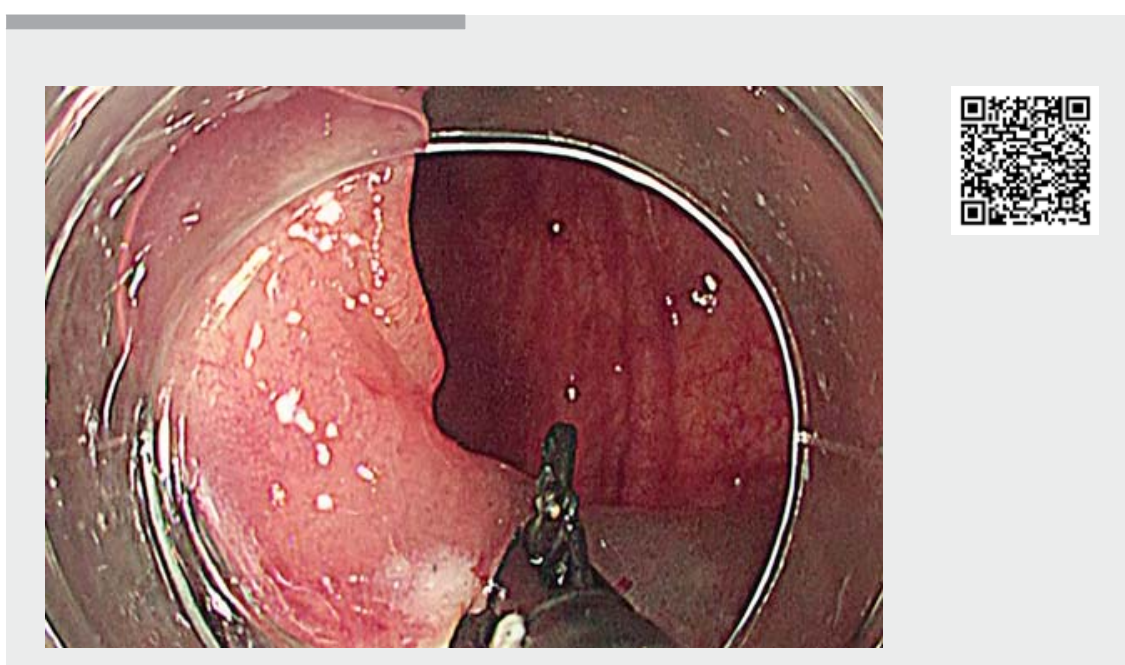

$\square$ Video 1 Video showing the usefulness of the paper cutting technique for overcoming instability when opening the pocket in the pocket-creation method.

The PCT is useful for overcoming instability when opening the pocket in the PCM.

Endoscopy_UCTN_Code_TTT_1AQ_2AD 

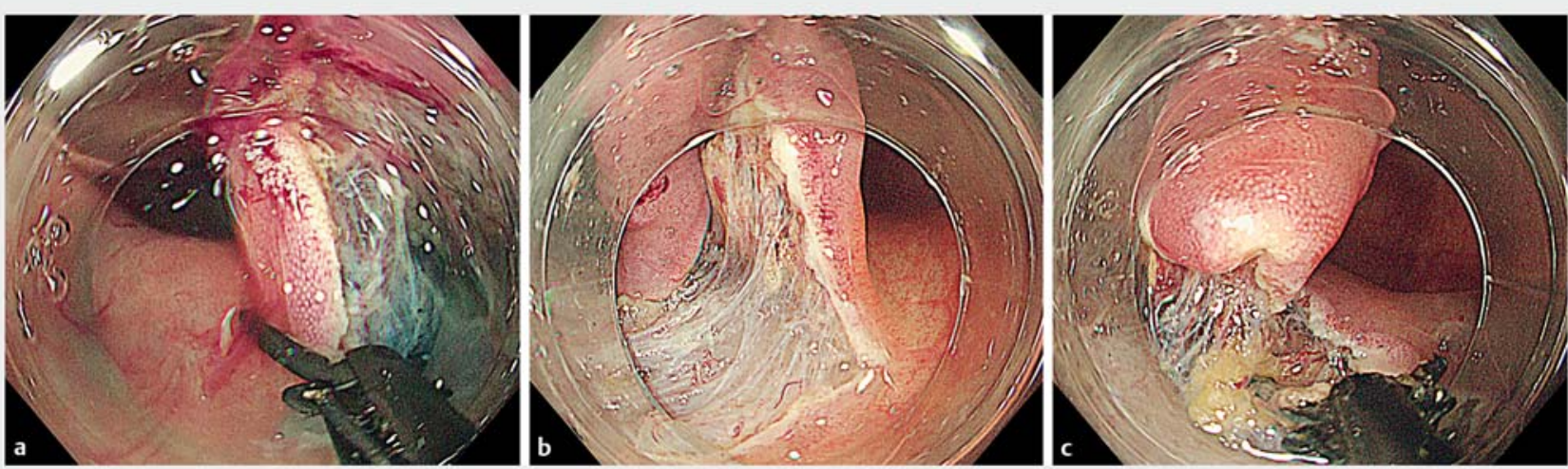

- Fig. 2 The normal mucosa and submucosa surrounding the lesion were cut in a manner similar to cutting paper (paper cutting technique). a Cutting on the left side. $\mathbf{b}, \mathbf{c}$ Cutting on the right side.

The authors

Satoshi Abiko, Ayumu Yoshikawa, Kazuaki Harada, Naoki Kawagishi, Itsuki Sano, Hisashi Oda, Takuto Miyagishima

Department of Gastroenterology, Kushiro Rosai Hospital, Kushiro, Japan

\section{Corresponding author}

\section{Satoshi Abiko, MD}

Department of Gastroenterology, Kushiro Rosai Hospital, 13-23, Nakazono-cho, Kushiro 085-8533, Japan

Fax: +81-154-257308

abiko1982@gmail.com

\section{References}

[1] Hayashi Y, Miura Y, Yamamoto H. Pocketcreation method for the safe, reliable, and efficient endoscopic submucosal dissection of colorectal lateral spreading tumors. Dig Endosc 2015; 27: 534-535

[2] Sakamoto H, Hayashi Y, Miura Y et al. Pocket-creation method facilitates endoscopic submucosal dissection of colorectal laterally spreading tumors, non-granular type. Endosc Int Open 2017; 5: E123-E129

[3] Akahoshi K, Minoda Y, Komori K et al. Endoscopic submucosal dissection using the "Clutch Cutter" for early esophageal squamous cell carcinoma. Endoscopy 2013; 45: 1035-1038

[4] Sakamoto N, Osada T, Shibuya T et al. The facilitation of a new traction device ( $\mathrm{S}-\mathrm{O}$ clip) assisting endoscopic submucosal dissection for superficial colorectal neoplasms. Endoscopy 2008; 40: E94-E95

\section{Bibliography}

DOI https://doi.org/10.1055/a-1024-3566

Published online: 25.10.2019

Endoscopy 2020; 52: E128-E129

(c) Georg Thieme Verlag KG

Stuttgart · New York

ISSN 0013-726X

\section{ENDOSCOPY E-VIDEOS}

https://eref.thieme.de/e-videos

回回 Endoscopy E-Videos is a free access online section, reporting 靣识 on interesting cases and new techniques in gastroenterological endoscopy. All papers include a high quality video and all contributions are freely accessible online.

This section has its own submission website at https://mc.manuscriptcentral.com/e-videos 